University of Wollongong

Research Online

Faculty of Social Sciences - Papers (Archive) Faculty of Arts, Social Sciences \& Humanities

$1-1-2019$

Teaching About Racial and Ethnic Diversity in Social Work Education: A Systematic Review

Katarzyna J. Olcon

University of Wollongong, kolcon@uow.edu.au

Dorie Gilbert

Prairie View A\&M University

Rose Pulliam

Texas State University

Follow this and additional works at: https://ro.uow.edu.au/sspapers

Part of the Education Commons, and the Social and Behavioral Sciences Commons

Research Online is the open access institutional repository for the University of Wollongong. For further information contact the UOW Library: research-pubs@uow.edu.au 


\title{
Teaching About Racial and Ethnic Diversity in Social Work Education: A Systematic Review
}

\author{
Abstract \\ Little of social work literature provides evidence of best teaching practices for preparing social work \\ students to work with clients from historically excluded racial and ethnic groups. A systematic literature \\ review was conducted to assess studies published in the United States during the 10-year period \\ (2007-2016) that examined: (1) social work educators' pedagogical interventions for teaching about racial \\ and ethnic diversity, (2) components of those interventions, (3) methodological designs to evaluate the \\ interventions, and (4) the students' learning outcomes. Following the systematic review protocol, the \\ authors identified and assessed twenty-five studies (qualitative, quantitative, and mixed-methods). The \\ studies reflected a variety of teaching interventions, such as diversity courses and projects, instructional \\ technology, and cultural immersion programs. While many reported positive student learning outcomes, \\ as a whole, the studies lacked methodological rigor and sound theoretical grounding. Although social \\ work education attempts to prepare students for multicultural practice, the field lacks an intentional and \\ systematic approach to teaching about racial and ethnic diversity and evaluating learning outcomes in \\ social work students. There is an urgency to expand the empirical evidence on social work diversity \\ education, particularly concerning teaching about race, racism, and Whiteness.

\section{Disciplines \\ Education | Social and Behavioral Sciences}

\section{Publication Details} \\ Olcon, K., Gilbert, D. J. \& Pulliam, R. M. (2019). Teaching About Racial and Ethnic Diversity in Social Work \\ Education: A Systematic Review. Journal of Social Work Education, online first 1-23.
}


Teaching about Racial and Ethnic Diversity in Social Work Education:

A Systematic Review

Katarzyna Olcoń, University of Wollongong

Dorie J. Gilbert, Norfolk State University

Rose M. Pulliam, Texas State University

Corresponding author: Katarzyna Olcoń, PhD, Social Work Lecturer, School of Health and

Society, Faculty of Social Sciences, University of Wollongong, South Western Sydney Campus,

33 Moore St, Liverpool, NSW 2170 Australia. Email: kolcon@uow.edu.au. 


\begin{abstract}
Little of social work literature provides evidence of best teaching practices for preparing social work students to work with clients from historically excluded racial and ethnic groups. A systematic literature review was conducted to assess studies published in the United States during the ten-year period (2007-2016) that examined: (1) social work educators' pedagogical interventions for teaching about racial and ethnic diversity, (2) components of those interventions, (3) methodological designs to evaluate the interventions, and (4) the students' learning outcomes associated with those teaching interventions. Following the systematic review protocol, the authors identified and assessed twenty-five studies (qualitative, quantitative, and mixed-methods). The studies reflected a variety of teaching interventions, such as diversity courses and projects, instructional technology, and cultural immersion programs. While many reported positive student learning outcomes, as a whole, the studies lacked methodological rigor and sound theoretical grounding. Although social work education attempts to prepare students for multicultural practice, the field lacks an intentional and systematic approach to teaching about racial and ethnic diversity and evaluating learning outcomes in social work students. There is an urgency to expand the empirical evidence on social work diversity education, particularly concerning teaching about race, racism, and Whiteness.
\end{abstract}

Keywords: social work education, social work students, multicultural education, diversity, race, ethnicity, racism, White privilege, Whiteness 
Teaching about Racial and Ethnic Diversity in Social Work Education: A Systematic Review

\section{Introduction}

Social work programs and educators play a crucial role in setting the tone and direction for the profession's discourse and practice with diverse communities; thus, effective diversity education, one that would prepare students to be competent practitioners, in social work education is critical. The importance of attending to racial and ethnic diversity in social work services has been widely discussed in the social work literature and incorporated in the Educational Policy and Accreditation Standards (EPAS) of the Council on Social Work Education ([CSWE], 2015). Upon graduation, social work students should be able to demonstrate the competency to "engage diversity and difference in practice," which means having the ability to "understand how diversity and difference characterize and shape the human experience and are critical to the formation of identity" (CSWE, 2015, p. 7). While the concept of diversity is extensive and includes many factors that shape an individual's identity, such as age, class, race, culture, and religion (CSWE, 2015), the focus of this article is on social work education specifically related to racial and ethnic diversity and its implications for social work practice.

There is a significant gap in understanding what constitutes a comprehensive and effective approach to teaching about racial and ethnic diversity. Because students are future service providers, this gap may have critical consequences. Clients from historically excluded racial and ethnic groups are disproportionally affected by negative life experiences, yet they are more likely to underuse or terminate social services, which, among other reasons, has been attributed to cultural insensitivity, marginalization and discrimination by service providers (e.g., Ahn, Miller, Wang, \& Laszloffy, 2014; Black, 2012; Jones, Hopson, Warner, Hardiman, \& James, 2015). These findings are further concerning when considered in light of the "discrepancy 
between the composition of the social work labor force and the demographic profile of many client groups" (NASW, 2011, p. 2). In fact, 69\% of active social workers in the United States are non-Hispanic Whites (Salsberg et al., 2017), and most will work in some capacity with clients from historically underrepresented racial and ethnic groups. The racial/ethnic imbalance between professional social workers and their clients, which is central to this discussion, is, in part, an artifact of the racial disparities in higher education. Although more students from historically underrepresented racial and ethnic groups are enrolling in social work programs, they currently represent only $35 \%$ of BSW graduates and $31 \%$ of MSW graduates (CSWE 2016).

Given the segregated nature of the U.S. society, White individuals, including White social work students, who are not generally encountering those racially and ethnically different from themselves may have a limited understanding of racism and sensitivity to the complexities of cross-racial and cross-cultural relationships (Rodenborg \& Boisen, 2013). Thus, this paper examines social work education strategies for teaching about racial and ethnic diversity, with a specific focus on interventions and outcomes related to learning about racism and Whiteness.

\section{Literature Review}

While social work aims to prepare students to work with diverse clients, the topics of racial and ethnic diversity and oppression remain on the periphery of social work education. Several authors have expressed a concern that race, racism, and Whiteness have not been sufficiently addressed in the social work curriculum (e.g., Abrams \& Gibson, 2007; Nylund 2006). Deepak, Rountree, and Scott (2015) conducted focus groups with 19 social work students, faculty, or staff (58\% White) who either taught, had taken, or had an interest in diversity courses to examine the importance of context and implicit curriculum in delivering diversity education in social work programs. Inadequate faculty preparation and discomfort with the topic of race 
emerged as significant barriers to successful diversity education (Deepak et al., 2015). In a study of 15 clinical social work faculty members ( $80 \%$ White) who taught advanced practice courses, Varghese (2016) found that the "majority of the participants do not think about or teach critically issues of race and racism, nor are they aware of the many opportunities to incorporate issues of race and racism into clinical social work practice material" (p. 144). Varghese (2016) elaborated that the faculty viewed race primarily in individual terms, focusing on the ethnic or cultural identity associated with it, yet they lacked knowledge about the history and current day social and economic effect of racism and its links to other forms of oppression. Similarly, based on a review of MSW course syllabi, Mehrotra, Hudson, and Self (2017) reported that diversity and social justice courses focused predominantly on individual-level self-awareness, i.e., understanding one's own social identities and developing an awareness of assumptions and biases as key competencies, as opposed to macro/structural analysis of systems of oppression.

The theoretical frameworks and strategies for teaching practice with diverse communities currently employed in social work education have increasingly come under criticism for predominantly focusing on the concept of cultural competence, defined as awareness, knowledge, and skills needed to work effectively with people across different cultures (Sue \& Sue, 2016) as opposed to anti-racist practice (Dominelli, 2008). Moreover, although the profession's mission calls for eliminating racism and oppression, the field has remained mostly silent on the role that Whiteness and Eurocentrism play in structural injustice. Jeyasingham (2012) explains that social work education should engage with Whiteness studies because they allow, among other reasons, "consideration of the invisible and hegemonic ways in which power generally operates" (p. 682). Rather than studying the cultural characteristics of nondominant racial and ethnic groups, the profession should require an anti-racist pedagogy and an analysis of 
Whiteness that looks inward at individual and institutional causes of inequalities and dominance (Abrams \& Gibson, 2007; Giroux, 2000). Moreover, social work services have been labeled as “missing the mark" (Williams, Simon, \& Bell, 2015, p. 56) in their approach to serving racial and ethnic communities, which often requires attention to structural oppression such as racism as opposed to focusing solely on individual interventions (Padilla, 1990; Viruell-Fuentes, Miranda, \& Abdulrahim 2012).

Consistent with the above concerns, only a tiny subset of the social work education literature in the United States explicitly addresses race, racism, and Whiteness (Abrams \& Gibson 2007; Dominelli, 2008; Nylund, 2006; Ortiz \& Jani, 2010; Pewewardy, 2007). Also, while much has been written in social work about cultural competence, multicultural practice, and diversity education, relatively little of this literature has embarked on empirically assessing the readiness of social work students for practice with clients from historically excluded racial and ethnic groups.

\section{Definitions}

It is important to provide a few definitions guiding our work. We view race as "an ideology about human differences" which "became a strategy for dividing, ranking, and controlling colonized people used by colonial powers everywhere" (American Anthropological Association, 2016), and racism as "a system of inequality and oppression based on race" (Varghese, 2016, p. 136). Ethnicity has been generally understood as "collective cultural identity (...) shared values and beliefs, the self-definition of a group, 'us"' (Spencer, 2006, p. 45). Critical Whiteness theory, also broadly referred to as Whiteness studies, analyzes and exposes the meaning and implications of Whiteness; rather than skin color alone, Whiteness implies a power structure, an ideology, and an individual identity, which is nevertheless, mostly invisible 
to White people (Jeyasingham, 2012). Whiteness thus serves as "a default standard ... [f]rom this color standard, racial/ethnic minorities are evaluated, judged and often found to be lacking, inferior, deviant or abnormal" (Sue, 2006, p. 15). Finally, multicultural/diversity education is a pedagogical approach focused on promoting principles of inclusion, pluralism, cultural relativism, critical thinking, and self-reflection with the goal of addressing racial inequality and injustice (Bell, 2007). Using a variety of perspectives, it emphasizes the history and experiences of marginalized groups as counternarratives to the dominant discourse and aims to give students the knowledge and skills needed to work toward social change (Bell, 2007).

\section{The Present Study}

Although the conceptual literature on the topic of multicultural social work practice and education is abundant, little of this literature provides the evidence of best teaching practices for preparing social work students to work with clients from historically excluded racial and ethnic groups. Moreover, no systematic review has been published to date in social work education to offer a summary of the existing teaching strategies focused on racial and ethnic diversity and their effectiveness. This systematic review will thus assess empirical studies to determine: (1) types of pedagogical interventions used to teach about racial and ethnic diversity in social work programs; (2) the components of those interventions, especially the inclusion of the topics related to race, racism, and Whiteness; (3) methodological designs to evaluate the interventions; and (4) reported student learning outcomes.

\section{Methods}

The purpose of the study was to find and review U.S.-based studies that documented social work education teaching strategies for preparing students to work with racially and ethnically diverse clients and reported student outcomes associated with those strategies. Systematic review procedures were used for all aspects of the search, retrieval, selection, and 
coding process of published studies meeting study inclusion criteria (see Campbell Collaborations Review Guidelines at www.campbellcollaboration.org; Littell, Corcoran, \& Pillai, 2008). A ten-year (2007-2016) timeframe was chosen for the review given the various cultural competence-related developments that have taken place in social work since 2007 . These include the NASW publications - Indicators for the Achievement of the Standards for Cultural Competence in Social Work Practice (2007; revised in 2015) and Institutional racism \& the social work profession: A call to action (De Silva et al., 2007), as well as the introduction of the CSWE Educational Policy 2.1.4 - "to engage diversity and difference in practice" (2008; revised in 2015).

\section{Study Eligibility Criteria}

Eligibility criteria for inclusion in the review included the following: (1) study conducted in the United States; (2) study published between January $1^{\text {st }}, 2007$ - December $31^{\text {st }}, 2016$; (3) study is empirical (quantitative, qualitative, mixed methods); (4) sample must include social work students (BSW and/or MSW); (5) study names and/or describes a pedagogical intervention specific to teaching about racial and ethnic diversity; and (6) study must include some evaluation component of the teaching intervention and report the learning outcomes for the students.

\section{Search Methods}

Research citations from January $1^{\text {st }}, 2007$ to December $31^{\text {st }}, 2016$ (ten years) were searched in seven electronic databases by two reviewers: (1) Social Service Abstracts; (2) PsycINFO; (3) Academic Search Complete; (4) Web of Science; (5) ERIC; (6) PubMed; and (7) Dissertations and Theses Global. Some of the search terms included: "social work education" OR "BSW education" OR "MSW education" OR "social work program*” AND divers* OR race OR ethnic* OR multicultural* OR cultur* OR "White privilege" AND "research study" OR quantitative OR qualitative OR "mixed methods". Next, a thorough review was conducted of the 
table of contents of five social work journals that publish articles referring to social work education and/or diversity in social work: (1) Journal of Social Work Education; (2) Journal of Teaching in Social Work; (3) Social Work Education, The International Journal; (4) Journal of Baccalaureate Social Work; and (5) Journal of Ethnic \& Cultural Diversity in Social Work.

Studies identified in the search process were screened independently by two reviewers, and any disagreements on whether a study should be included in the review were discussed between the two reviewers. If the reviewers were unable to arrive at an inclusion/ exclusion decision, a third reviewer was asked to screen the study and assist in making the decision. After the selection of relevant studies, their references were hand searched by two reviewers to determine if any other studies fit the inclusion criteria. Finally, the first authors of the selected articles were contacted via email to inquire about other potential studies on the topic that had not already been identified.

In the last step, the studies selected for full-text review were coded to collate and analyze the results. Coding categories included: (1) type of report; (2) theoretical framework; (3) study design; (4) demographic information; (5) pedagogical intervention descriptors (e.g., type, length, setting, components, whether racism and Whiteness had been addressed); and (6) intervention outcomes/significance (e.g., improved scores on cultural competence measures). Additionally, two types of quality indicators were used depending on the study methodology. CASP Qualitative Research Checklist (Critical Appraisal Skills Programme, 2017), which includes questions such as "Is a qualitative methodology appropriate?" (p. 2) and "Was the data analysis sufficiently rigorous?" (p. 5), was used for qualitative studies and the qualitative component of mixed methods studies. Quantitative studies and the quantitative component of mixed methods studies were assessed with the Standard quality assessment criteria for evaluating primary 
research papers from a variety of fields (Kmet, Lee, \& Cook, 2004) which includes questions about the robustness of outcome measure(s), controlling for confounding variables, justification of analytic method, and whether the estimate of variance was reported, among others. Quality scores were not used to exclude studies, but to identify their strengths and weaknesses. Two reviewers coded the studies independently, and any disagreements in coding were reconciled in a subsequent discussion.

\section{Results}

Figure 1 shows the "preferred reporting items for systematic reviews and meta-analyses" based on the PRISMA model (Moher, Liberati, Tetzlaff, \& Altman, 2009). The electronic databases yielded a total of 2,401 titles and abstracts, and an additional 14 were identified through journal hand searches. A search of the reference lists of the selected articles yielded 18 additional studies. Email inquiries were sent to 25 authors of the selected articles, and five of them identified 6 new studies. A total of 2,439 titles and abstracts were thus identified and read to assess their relevance to the present systematic review. Following this search process, and after removing duplicates, the full texts of 191 unique reports were retrieved for screening. A total of 145 studies were excluded at the screener level for not meeting the study criteria (e.g., focus on social work providers or faculty as opposed to students, lack of an evaluation component, focus on countries other than the U.S.). Additional 21 articles were excluded after the reviewers read the full-text, because, among other reasons, the evaluation component either lacked an empirical basis or was solely based on anecdotal evidence. Twenty-five (25) studies went on for coding. 
Insert Figure 1 about here

The majority $(76 \%, \mathrm{n}=19)$ of the articles were published in social work journals, $16 \%$ appeared in non-social work journals $(n=4)$, and $8 \%$ were dissertations $(n=2)$. The most frequent social work journal was Journal of Teaching in Social Work $(\mathrm{n}=6)$, followed by The Journal of Baccalaureate Social Work $(\mathrm{n}=4)$, and Journal of Social Work Education $(\mathrm{n}=3)$, and Journal of Ethnic \& Cultural Diversity in Social Work $(\mathrm{n}=3)$. Two were published in Social Work Education, The International Journal, and one study was published in Affilia: Journal of Social Work and Women. The non-social work journals included: Journal of Technology in Human Services $(\mathrm{n}=2)$, Multicultural Perspectives $(\mathrm{n}=1)$, and International Journal of Humanities and Social Science $(\mathrm{n}=1)$. The principal objectives of the studies can be summarized as: (1) to evaluate the effectiveness of a diversity-focused pedagogical intervention; and (2) to explore students' learning outcomes in response to diversity-focused pedagogical intervention.

\section{Methodological Characteristics}

The study eligibility criteria allowed for all methodologies and designs to be included in the review, given that a methods section explaining the data collection and analysis was included. Fifty-two percent $(n=13)$ of the studies were quantitative, $32 \%(n=8)$ were qualitative, and $16 \%(\mathrm{n}=4)$ were mixed-methods.

The majority $(\mathrm{n}=11)$ of quantitative studies and the quantitative components of mixed methods studies were based on pre- and post-surveys administered only to the students who received the pedagogical intervention of interest. Six studies (24\%) included a comparison 
group; they were either pre- and posttest nonequivalent, quasi-experimental designs or posttest only designs. A variety of measures were utilized across the studies: the Multicultural Awareness-Knowledge-and Skills Survey (MAKSS), the Color-Blind Racial Attitudes Scale (COBRAS), the California Brief Multicultural Competence Scale (CBMCS), the Social Work Cultural Competencies Self-Assessment, the Oppression Exists Measure (OEM), the Modern Racism Scale [MRS], the Multicultural/ Multiracial Experience Inventory (MEI), the Multiculturally Responsive Index (MRI), and others. Five studies used measures that the authors specifically designed for the study, and four studies used more than one measure. In addition to the descriptive analyses, the t-test was the most commonly used data analysis procedure $(\mathrm{n}=12)$. Other methods included ANOVA $(n=6)$, regression $(n=2)$, Chi-square test $(n=2)$, Wilcoxon Signed Ranks Test $(n=2)$, MANOVA $(n=2)$, and Pearson Correlation $(n=2)$.

The most common data source in qualitative studies and the qualitative component of mixed methods studies was written work collected from the students during or after the intervention: journals/reflection papers $(n=4)$, classroom papers/assignments $(n=2)$, online discussion forums $(\mathrm{n}=2)$, student open-ended written feedback/evaluation after an activity $(\mathrm{n}=$ 3), or a combination of these. Only two studies used individual or focus groups interviews, and two included field observations, e.g., fieldnotes from students' panel discussions. Content analysis was the most common qualitative data analysis method ( $\mathrm{n}=5$ studies), and others included grounded theory $(n=2)$, thematic analysis $(n=1)$ and phenomenology $(n=1)$. Four of the qualitative and mixed methods studies either used some other form of data analysis approach or did not specify their data analysis method.

The most frequently utilized theoretical framework to guide the research studies was the cultural competence model; $32 \%$ of studies used some form of this model. Some of the other 
guiding theories included social constructivist theory $(8 \%)$, the transcultural perspective (8\%), and the transformational learning theory $(8 \%)$. Several other frameworks were used once, including the White racial identity development model, critical pedagogy, critical race theory, intergroup contact theory, cultural humility model, dual perspective, etc. (for brief descriptions see Table 1$)$. Nearly one-quarter $(24 \%)$ of the studies did not specify their guiding theoretical or conceptual framework.

Insert Table 1 about here

\section{Sample Characteristics}

Total sample sizes for all studies ranged from six to 386, with the average size of 98.9 $(\mathrm{SD}=95.7)$. The sample size in quantitative studies ranged from 11 to $386(\mathrm{M}=147, \mathrm{SD}=$ 104.5), in qualitative studies from six to $65(\mathrm{M}=28, \mathrm{SD}=20)$, and in mixed methods studies from 22 to $179(\mathrm{M}=83.8, \mathrm{SD}=68.9)$. Eighty-four percent of the studies had samples that were only social work students; out of this $43 \%$ of had only BSW students, $38 \%$ of studies were MSW only, and 19\% included both groups. Sixteen percent of the studies included students from other majors such as sociology, criminology, human development, and family services. In two of these cross-disciplinary studies, social work students were the minority, representing only $27 \%$

(Colvin-Burque, Zugazaga, \& Davis-Maye, 2007) and 23\% of the sample (Mapp, 2012). Concerning race and ethnicity, non-Hispanic Whites were the predominant group; on average $70.6 \%$ of the samples were White. African Americans and Latinos represented nine percent each of the total sample, Asians - four percent, Native Americans - one percent, biracial/multiracial students - two percent, and others (e.g., African Caribbean and Middle Easterners) two percent. 
The remaining two percent were unknown. Five studies failed to provide some or all of the demographic information of the sample, and the above averages were calculated excluding those studies. The samples were predominantly female, with percentages ranging from $60 \%$ to $100 \%$ and an average of $82.7 \%$. Finally, because of inconsistent or missing data on age, the average age was not calculated; however, the age range was from 18 to over 52, and in general, the majority of the participants were in their 20 s and early 30 s.

Insert Table 2 about here

\section{Interventions Characteristics}

The pedagogical interventions aimed to engage students in reflecting on cultural differences and their implications for social work practice, change students' racial attitudes, and increase their cultural competence, among others. The duration of the interventions ranged from one class period to one semester, with $56 \%$ being one semester long. Only two studies provided information about the characteristics of the class instructors/facilitators of these pedagogical interventions, with one study being co-taught by two White women and another course was cotaught by one Native American and two White instructors. The interventions can be grouped into four categories: (1) diversity/cultural competence courses; (2) diversity/cultural competence projects, (e.g., intergroup dialogue); (3) instructional technology, (e.g., videos and virtual communities); and (4) cultural immersion programs such as study abroad programs (See Table 2 for details).

Diversity/cultural competency courses. Seven studies (28\%) evaluated the effectiveness of social work diversity/cultural competence courses or equivalent (e.g., Cultural 
Diversity Practice, The Culturally Responsive Social Work, Facing Racism in a Diverse

Nation). Four of the studies detailed the course components, including an ethnographic family of origin case study, interview with a classmate about racial and ethnic identity formation, analysis of vignettes with multicultural issues, and self-reflective journaling.

Diversity/cultural competence projects. Eleven studies (44\%) described and evaluated some special projects aiming to teach students about racial and ethnic diversity. Although these projects were usually incorporated into diversity courses or other parts of the BSW or MSW curriculum, the study only evaluated the effect of the particular project. Some of these projects were Ethnic Roots, Self and Other Awareness Project, Intergroup Dialogue, Consciousnessraising Group, and Cultural Genogram (for a complete list and descriptions, see Table 2). Some of the activities required of the participants were: interviewing family or friends, writing an essay about their ethnic/racial background, attending a cultural interaction or event, preparing a family genogram, attending peer-facilitated intergroup dialogue groups, class discussions about racism, power, White privilege, and oppression, among others.

Instructional technology. Four studies (16\%) evaluated teaching interventions centered around media and technology. These interventions utilized specifically selected YouTube videos, movies, avatars and virtual communities, and online diversity forums; and these were usually incorporated into a diversity course or other social work course. Deepak and Biggs (2011) detailed the Intimate Technology intervention where the class viewed YouTube videos about New Orleans after Hurricane Katrina, and other videos and songs about personal experiences with racism. Difficult Digital Dialogues incorporated Twitter and Skype to facilitate diversity learning among social work students from a predominantly White institution and a historically black college/university (Brady, Sawyer, \& Crawford Herrera, 2016). Three courses used online 
forums to facilitate discussions related to race, ethnicity, and social class (Lee, 2014; Lee, Brown, \& Bertera, 2010; Lee \& Priester, 2014); and a hybrid/online course used avatars (figures representing a particular person in computer games), virtual communities, and cocktail party exercises to teach about diversity (Lee, 2014).

Social work cultural immersions programs. A cultural immersion experience was the focus of three studies (12\%). Two of the studies described and evaluated international cultural immersions, and one was a domestic immersion based in Louisiana and Appalachia (Quinn-Lee \& Olson-McBride, 2012). Two international immersions took place in Thailand (Mapp 2012; Schuldberg et al., 2012); the other immersion countries were Ireland, Vietnam, Costa Rica, and Ecuador (Mapp, 2012). These cultural immersions were short-term, mostly summer study abroad programs. They included some service learning component, visits to social service agencies, and excursions to popular religious, historical, cultural sites.

Addressing racism and Whiteness. Sixty-four percent of the interventions $(n=16)$ addressed race and racism, and 24\% $(\mathrm{n}=6)$ included content on Whiteness, such as White privilege and related concepts. Some ways the interventions incorporated issues related to race and racism were: dialogue about Ferguson and Trayvon Martin (Brady et al., 2016), analysis of local institutional racism (Saleh, Anngela-Cole, \& Boateng, 2011), interview with a classmate about racial and ethnic identity (Hall \& Theriot, 2007; 2016); tour of a former plantation's slave quarters combined with visit to an African American museum (Quinn-Lee \& Olson-McBride, 2012); and questions about race and prejudice on a Cultural Genogram (Warde, 2012). The topic of White privilege was covered in an intergroup dialogue (Lopez-Humphreys, 2011), a consciousness-raising group (Giesler, 2013), a classroom discussion (Deepak \& Biggs, 2011), by visiting non-White neighborhoods and a follow-up discussion (Loya \& Cuevas, 2010), and a film 
and a community panel (Lee \& Priester, 2014). Three interventions were entirely focused on racism, anti-racism, and White privilege (Deepak \& Biggs, 2011; Loya \& Cuevas, 2010; Saleh et al., 2011).

\section{Findings}

Based on the study findings, in $56 \%$ of the studies $(n=14)$, the pedagogical interventions had a positive effect on student learning about racial and ethnic diversity and cultural competence or related outcomes. For example, Williams-Grey (2014) found that students demonstrated enhanced self- and cultural awareness after participating in an Ethnic Sharing activity where some students shared stories about their family, culture, values, and experiences, and the rest of the class listened. Similarly, following some of the diversity/cultural competence courses, there was a significant increase in the students' scores on diversity awareness (Anderson, Hayashi, \& Frost, 2009), cultural competence (Block, Rossi, Allen, Alschuler, \& Wilson, 2016), multicultural awareness, knowledge, and skills (Hall \& Theriot, 2016; Melendez, 2007), and positive racial attitudes (Loya \& Cuevas, 2010).

In $40 \%$ of the studies $(n=10)$, the results were mixed; students showed a positive learning outcome in some but not all of the constructs of interests. For example, Drabble, Sen, and Oppenheimer (2012) found that students significantly increased their cultural knowledge, positioning, and reflexivity, but there was no change in their understanding of power, privilege, and oppression. A few studies reported a positive change in students' understanding of diversity concepts and issues, but not in their comfort level in working with diverse clients (Lee, 2014; Lee \& Priester, 2014). Specifically, Lee (2014) reported that students who participated in a "cocktail party exercise," where they interacted with diverse people in a virtual community, had better outcomes in learning about diversity than students in a traditional diversity course. 
Nevertheless, comfort level in working with diverse populations was higher among the traditional classroom students.

Finally, in one study, the intervention yielded no major outcomes; the researchers reported no changes in students' perspectives about privilege, diversity, or difference (Brady et al., 2016). Further, another study reported a positive effect on students who participated in diversity-focused online discussion forums; however, some of the forums proved to have harmful effects when students engaged in offensive dialogue about race and were not redirected by the class instructor (Lee et al., 2010). The authors emphasized that careful monitoring is necessary to ensure a productive learning process about diversity through online methods.

Learning about racism and Whiteness. Forty-eight percent of the studies $(n=12)$ reported findings related to race and racism. For example, some of the qualitative studies had themes specific to race-related learning, such as "understanding racism and anti-racism" (Deepak \& Biggs, 2011, p. 52) and "understanding the role of race in social work process" (Bender, Negi, \& Fowler, 2010, p. 47). Other studies described the changes in students' awareness of racial privilege and institutional discrimination as measured by the COBRAS (Colvin-Burque et al., 2007; Loya \& Cuevas, 2010). Finally, Giesler (2013) found that the topic of race and ethnicity, compared to other social identities, was the most difficult for students to discuss in their consciousness-raising groups. It is also important to point out, that although $64 \%$ of the studies addressed race and racism in describing their pedagogical intervention, only $48 \%$ reported on the related learning outcomes in the results.

In terms of learning about Whiteness, $20 \%$ of the studies $(n=5)$ reported observations about this in the results section. Bender et al. (2010), for example, found that White students were able to reflect on the meaning of Whiteness and the many privileges linked to it, and 
Deepak and Biggs (2011) reported that White students found hope in learning about anti-racism and becoming an ally, as opposed feeling guilty about being White.

Reflective, experiential, and emotional learning. Given that different teaching methods, such as the experiential or the affective domain teaching, have been recommended by scholars to prepare students for culturally competent practice (Cramer, Ryosho, \& Nguyen, 2012; Sue \& Sue, 2016; Weaver, 1998), the studies were also coded for the inclusion of reflective, experiential, and emotional teaching. Eighty percent of the interventions included at least one of those teaching methods, $56 \%$ included at least two, and $16 \%$ included all three types.

Reflective learning, which included activities such as writing self-reflective journals, was used in $76 \%$ of the interventions. For example, following the Cultural Genogram project which required a reflection on their family history, Warde (2012) found a higher level of cultural awareness and sensitivity in the students. Sixty-eight percent of the interventions used some experiential learning strategy, such as cultural immersion experiences, volunteering, and interviewing classmates. Loya and Cuevas (2010) found that following a variety of experiential learning activities about racism and inequality, there was a significant change in student cultural awareness and racial attitudes. Results also showed that immersion in a different culture helped students became more comfortable with and appreciative of differences (Quinn-Lee \& OlsonMcBride, 2012), increased cross-cultural adaptability (Mapp, 2012) and developed the awareness of ethnocentrism (Schuldberg et al., 2012). Finally, emotional learning, which focuses on people's ability to empathize with the feelings and experiences of others (Fox, 1983), was incorporated in $24 \%$ of the studies. For example, students who learned about other peoples' experiences with racism through images, music, and personal stories, experienced deep 
emotional responses such as anger and sadness. This in turn helped them to be more engaged in the learning process and understand racism in more depth (Deepak \& Biggs, 2011).

Differences among student groups. Another indicative finding in the studies was related to the demographic differences among students in learning about diversity. Thirty-two percent of the studies $(n=8)$ reported some differences in student outcomes based on student demographics. Students from historically underrepresented racial and ethnic groups were found to have a significantly higher level of awareness about diversity (Anderson et al., 2009) and White privilege (Colvin-Burque et al., 2007), and reported greater comfort in venturing outside their own social and cultural groups (Saleh et al., 2011) compared to White students. However, Melendez (2007) found that the increase in cultural awareness following the diversity course was significantly higher in White students, given it was often the first time they were exposed to the topic of diversity. Similarly, Lopez-Humphreys (2011) reported that White students gained substantially more from the intergroup dialogue activity than non-White students. Finally, students majoring in social work were found to have significantly more awareness of institutional discrimination, racial issues, and color-blind attitudes (Colvin-Burque et al., 2007), and more knowledge and positive attitudes toward diversity (Saleh et al., 2011) as compared to non-social work students.

\section{Study Quality}

Using the Kmet et al. (2004) scale, the quality of the quantitative studies and the quantitative component of mixed methods studies ranged from 9/22 to 20/22, with the average scores equaling to $15.7 / 22$. Overall, quantitative and the quantitative components of mixed methods studies scored better on questions about research objectives and justification of their methods. However, they performed less well in terms of defining outcomes measures and 
controlling for confounding variables. The qualitative studies and the qualitative component of mixed methods studies were evaluated with the CASP Qualitative Research Checklist. Although no precise scoring system exists for the checklist (CASP, 2017), several patterns were observed. The checklist includes 10 questions that can be answered as either "yes," "no" or "can't tell." On average, only 5.5 questions were answered as "yes", indicating rather low quality of the studies. The qualitative studies generally explained the aims of the research and recruitment strategy well, but the methods and data analysis were often not sufficiently rigorous.

\section{Discussion}

The purpose of this systematic review was to examine empirical studies that assessed how social work educators and programs teach students about racial and ethnic diversity. Twenty-five studies were identified and they described and evaluated a variety of pedagogical interventions including: diversity courses, special projects, instructional technology, and cultural immersion programs. In most of the included studies, the pedagogical intervention had a positive effect on students' development of cultural competence or a related construct. For example, after participating in growth groups, groups aiming to help student gain self-awareness and discuss and reduce prejudice, students showed a significant change in awareness of personal prejudice, comfort level in interacting with and confronting others around prejudices and developing a strategy to reduce personal prejudices (Phillips et al., 2011). Similarly, students were found to develop awareness of personal biases and how these might affect social work practice with diverse clients as a result of the Proverbs Across the Globe project, where students analyzed proverbs and interviewed someone from a different culture (Rahill et al., 2016).

Although indicative, the findings should be interpreted cautiously due to methodological and theoretical weaknesses in the design of many of the reviewed studies. Some of the major 
problems seen in many studies included: a) lack of comparison group; b) the use of unstandardized measures with unclear validity and reliability in quantitative studies and the quantitative components of mixed methods studies; c) lack of clarity about data analysis process in qualitative studies; d) incomplete description of findings or conclusions not fully supported by the results; e) relying on self-report measures, journals, and class assignments, all of which are prone to social desirability bias, particularly as related to cultural competence (Larson \& Bradshaw, 2017); and f) lack of longitudinal design to assess whether the outcomes of the teaching interventions are then translated into practice.

In conclusion, the study revealed that social work education lacks an intentional and systematic approach to teaching about racial and ethnic diversity and to evaluating student learning outcomes related to these concepts. Despite the abundance of conceptual literature on the topic and the EPAS standards (CSWE, 2015), there is a relatively small number of studies reporting on racial and ethnic diversity-related pedagogical interventions. It is important to note here that nine additional articles had to be excluded from the review because they lacked a methods section. Although they looked promising at first, the evaluation component of the intervention was often anecdotal, or the steps involved in data collection and analysis were obscure, and therefore they could not be coded. Among the coded studies, there was a wide range of approaches taken to teach this topic, varying all the way from working with street children in another country to participating in virtual communities and using avatars. None of the reviewed studies was a replication of an intervention tested by another author, except for Hall and Theriot $(2007,2016)$. Only a few of the studies, however, described their interventions in sufficient detail that would allow for replication. 
Additionally, the studies also differed in how they evaluated the teaching outcomes. Across the quantitative and mixed methods studies, for example, multiple scales were used, and they often measured related but not the same constructs (e.g., the Multicultural AwarenessKnowledge-and Skills Survey versus the Color-Blind Racial Attitudes Scale). Moreover, there were a few limitations related to placing the studies within some theoretical framework. Many studies made no mention of theory; others introduced a theory but failed to follow through on how the theory related to the teaching intervention or methodology. Moreover, the most frequently used guiding framework, the cultural competence model, has itself been criticized for lacking theoretical grounding (e.g., Wear, 2003).

Finally, it is important to note that in many of the studies, the samples were predominantly White females, and it is likely that the described interventions may not apply to more diverse student populations. Additionally, except for providing the region of the country, the studies frequently lacked detailed information on the context, notably whether the university was a predominantly White institution, public or private, or rural or urban campus.

\section{Implications}

Before discussing the potential implications of this systemic review, we would like to point out some limitations of the current study. First, studies were included in the review independently of their methodological rigor. Restricting the review to only highly rigorous studies would not allow the review to take place, given the state of the existing empirical knowledge base. Second, we included studies independently of the methodology and design, which was intentional to show the full picture of social work education focused on racial and ethnic diversity; however, this made the synthesizing of the results and establishing trends in the 
studies more difficult. We also acknowledge that other researchers would potentially code for different pieces of information and analyze the studies from a different perspective.

Despite these limitations, the review provided several insights on the current state of the empirical literature and the directions for future research. First, the review revealed the urgency to expand the empirical evidence regarding effective strategies for teaching about racial and ethnic diversity in social work programs. Social work researchers and educators need to build a body of knowledge that delineates best teaching practices, assignments, and content material that will prepare students for working effectively and respectfully across racial, ethnic, and cultural differences. The promising pedagogical interventions should be tested and replicated to create a database and a toolkit for social work educators on how to best teach diversity-related topics. This is particularly crucial for pedagogy on racial and ethnic diversity, as these topics have been found the most difficult to discuss in a classroom (Giesler, 2013), and can result in discomfort, tension, and resentment, particularly in White students (Abrams, \& Gibson, 2007; Gair, 2016).

To be able to build this empirical knowledge base, however, social work education needs a unified conceptualization of what constitutes social work diversity education: its purpose, essential components, and desired outcomes. As the study by Jani, Osteen, and Shipe (2016) shows, there are many ways of defining what constitutes the ability to work effectively with people from different backgrounds, and "cultural competence itself is a flawed concept" (p. 316). For example, social work educators rarely incorporate an analysis of Whiteness, including White culture, White privilege, and White racism into their classrooms, which, in turn, inherently perpetuates the oppressive racial social structures that social work hopes to resolve (Abrams \& Gibson, 2007). As Williams (2006) reminds: “The lack of a coherent theory base for cultural competence makes it difficult to evaluate its effectiveness in practice" (p. 210). To effectively 
prepare social work students for practice with historically excluded racial and ethnic groups, we need a sound theoretical foundation of what is it that we are trying to teach and how we will know if the students are on the right path to developing the needed knowledge and skills. Critical race theory, critical Whiteness theory, and anti-racist pedagogy offer viable options for use in diversity education (Abrams \& Moio, 2009; Nylund, 2006; Ortiz \& Jani, 2010; Pulliam, 2017).

From a methodological perspective, there is a need for more rigorous research methods and increased transparency about the data analysis procedures. It seems crucial that future social work education research includes comparison groups and longitudinal components to assess the effectiveness of teaching interventions over time. Large-scale, multisite, and diverse-sample studies are needed to compare the learning outcomes and experiences of students from a variety of backgrounds and in different educational and geographical contexts. There is also ample room for future researchers to design theoretically grounded, valid, and reliable outcome measures, which could be used consistently for social work education and research purposes, allowing for comparison of student learning outcomes across different teaching interventions.

The systematic review's findings also seem to imply that graduating social work students may not be adequately prepared to practice competently across racial and ethnic differences. Evidence-based teaching interventions and tools to assess student's readiness to practice with historically excluded racial and ethnic groups are urgently needed in social work education. This in turn has implications for social work educators. Given that racial diversity-related topics are highly politically, ideologically, and emotionally charged and provoke many pedagogical tensions and struggles (Daniel, 2011), instructors may require additional preparation to teach and facilitate dialogues about race, racism, and Whiteness. Mediation and group work skills may be needed in order to create an honest, safe, and welcoming classroom environment where students 
of different racial backgrounds can engage in a difficult dialogue. Students from historically underrepresented racial and ethnic groups should not feel tokenized and asked to speak on behalf of their entire racial or ethnic group. White students, on the other hand, should not be blamed for the historical roots of racial and ethnic oppression but rather challenged to engage in a critical reflection and anti-racism actions. Workshops and trainings such as The National Intergroup Dialogue Institute (University of Michigan, 2018), and Undoing Racism (The People's Institute for Survival and Beyond, 2018) can assist the faculty in enhancing their skills in these areas. Teaching partnerships between instructors from historically underrepresented racial and ethnic groups and White instructors (Fox, 1983; Gollan \& O'Leary, 2009) may address issues of White students challenging or ignoring non-White instructors and White instructors being perceived as lacking credibility to teach about race and racism.

\section{Conclusion}

The work of the authors cited in Table 2 is an essential start to the urgently needed line of research that would help ensure that social work programs adequately prepare students to engage in practice with diverse populations (CSWE, 2015). Currently, many questions remain unanswered regarding the purpose, components, and expected outcomes of pedagogical interventions focused on racial and ethnic diversity. The same emphasis that the social work field has placed on evidence-based practice is needed in social work classrooms - we need evidencebased diversity education. Social work students are the future service providers who will serve diverse clients and in a variety of work contexts. Their level of understanding of diversity and their preparedness to work with historically underrepresented racial and ethnic groups will inevitably influence the quality of their services. An authentic commitment to providing highquality services to clients from historically excluded racial and ethnic groups must translate to 
best teaching practices in social work classrooms and a research agenda that provides a sound foundation for social work education's anti-racism goals.

\section{References}

Abrams, L. S., \& Gibson, P. (2007). Reframing multicultural education: Teaching White privilege in the social work curriculum. Journal of Social Work Education, 43(1), 147160.

Abrams, L. S., \& Moio, J. A. (2009). Critical Race Theory and the cultural competence dilemma in social work education. Journal of Social Work Education, 45(2), 245-261.

Ahn, Y., Miller, M., Wang, L., \& Laszloffy, T. (2014). 'I didn't understand their system, and I didn't know what to do': Migrant parents' experiences of mandated therapy for their children. Contemporary Family Therapy: An International Journal, 36(1), 25-40.

Allport, G. W. (1954/1979). The nature of prejudice. Cambridge, MA: Addison-Wesley. American Anthropological Association. [AAA]. (2016). AAA statement on race. Retrieved from http://www.americananthro.org/ConnectWithAAA/Content.aspx?ItemNumber=2583

Anderson, W., Hayashi, R., \& Frost, C. J. (2009). Measuring the diversity awareness of social work students: The Dual Perspective Inventory. Journal of Teaching in Social Work, $29(3), 258-270$.

Bender, K., Negi, N., \& Fowler, D. N. (2010). Exploring the relationship between self-awareness and student commitment and understanding of culturally responsive social work practice. Journal of Ethnic \& Cultural Diversity in Social Work, 19(1), 34-53.

Bell, L. A. (2007). Theoretical foundations for social justice. In M. Adams, L. A. Bell \& P. Griffin (Eds.), Teaching for diversity and social justice (2nd ed.). (pp. 1-5). New York, NY US: Routledge/Taylor \& Francis Group. 
Black, H. K. (2012). The influence of African American elders' belief systems on health interactions. Journal of Religion \& Spirituality in Social Work, 31(3), 226-243.

Block, A. M., Rossi, A. N., Allen, C. D., Alschuler, M., \& Wilson, V. B. (2016). Assessing cultural competence in a BSW student population. Social Work Education, 35(6), 643658. doi:10.1080/02615479.2016.1158248

Brady, S. R., Sawyer, J. M., \& Crawford Herrera, S. (2016). Preparing social work students to practice in diverse communities through difficult digital dialogues. Journal of Technology in Human Services, 34(4), 376-393. doi:10.1080/15228835.2016.1250244

Chestang, L. (1976). Environmental influences on social functioning: The Black experience. In P. Cafferty \& L. W. Chestang (Eds.), The diverse society: Implications for social policy (pp. 76-87). Washington, DC: National Association of Social Workers Press.

Colvin-Burque, A., Zugazaga, C. B., \& Davis-Maye, D. (2007). Can cultural competence be taught? Evaluating the impact of the SOAP model. Journal of Social Work Education, 43(2), 223-242.

Council on Social Work Education [CSWE]. (2008). Educational policy and accreditation standards. Retrieved from https://cswe.org/getattachment/Accreditation/Standards-andPolicies/2008-

EPAS/2008EDUCATIONALPOLICYANDACCREDITATIONSTANDARDS(EPAS)08-24-2012.pdf.aspx

Council on Social Work Education [CSWE]. (2015). Educational Policy and Accreditation Standards. Retrieved from http://www.cswe.org/getattachment/Accreditation/Accreditation-Process/2015EPAS/2015EPAS_Web_FINAL.pdf.aspx 
Council on Social Work Education [CSWE]. (2016). Annual statistics on social work education in the United States: 2015. Retrieved from http://www.cswe.org/File.aspx?id=94118

Cramer, E. P., Ryosho, N., \& Nguyen, P. V. (2012). Using experiential exercises to teach about diversity, oppression, and social justice. Journal of Teaching in Social Work, 32(1), 1-13.

Crenshaw, K. (1991). Mapping the margins: Intersectionality, identity politics, and violence against women of color. Stanford Law Review, 43(6), 1241-1299.

Critical Appraisal Skills Programme [CASP] (2017). CASP Qualitative Research Checklist. Retrieved from http://docs.wixstatic.com/ugd/dded87_25658615020e427da194a325e7773d42.pdf

Daniel, C. (2011). Lessons learned: Pedagogical tensions and struggles with instruction on multiculturalism in social work education programs. Social Work Education, 30(3), 250265. doi:10.1080/02615471003789829

Delgado, R., \& Stefancic, J. (2001). Critical race theory: An introduction. New York, NY: New York University Press.

De Silva, E. C., Jackson, V., Oldman, V., Schachter, R., Wong, J., Lopez, L., \& Richards, D. (2007). Institutional racism and the social work profession: A call to action. Washington, DC: National Association of Social Workers. Retrieved from https://ncwwi.org/files/Cultural_Responsiveness__Disproportionality/Institutional_Racis m_and_the_Social_Work_Profession.pdf

Deepak, A. C., \& Biggs, M. J. G. (2011). Intimate technology: A tool for teaching anti-racism in social work education. Journal of Ethnic \& Cultural Diversity in Social Work, 20(1), 3956. 
Deepak, A. C., Rountree, M. A., \& Scott, J. (2015). Delivering diversity and social justice in social work education: The power of context. Journal of Progressive Human Services, 26(2), 107-125. doi:10.1080/10428232.2015.1017909

Dominelli, L. (2008). Anti-racist social work (3rd ed). London: Palgrave Macmillan.

Drabble, L., Sen, S., \& Oppenheimer, S. Y. (2012). Integrating a transcultural perspective into the social work curriculum: A descriptive and exploratory study. Journal of Teaching in Social Work, 32(2), 204-221. doi:10.1080/08841233.2012.670087

Fox, J. R. (1983). Affective learning in racism courses with an experiential component. Journal of Education for Social Work, 19(3), 69-76.

Freire, P. (1970). Pedagogy of the oppressed. (M. B. Ramos, Trans.). New York, NY: Seabury.

Gair, S. (2016). Critical reflections on teaching challenging content: Do some students shoot the (White) messenger? Reflective Practice, 17(5), 592-604.

Giesler, M. A. (2013). Teaching note: cultural immersion in the classroom: using consciousnessraising groups to enhance diversity competence. The Journal of Baccalaureate Social Work, 18, 173181.

Giroux, H. (2000). Insurgent multiculturalism and the promise of pedagogy. In E.M. Duarte \& S. Smith (Eds), Foundational Perspectives in Multicultural Education (pp. 195-212). New York, NY: Longman.

Gollan, S., \& O'Leary, P. J. (2009). Teaching culturally competent social work practice through black and White pedagogical partnerships. Social Work Education, 28(7), 707-721. doi:10.1080/02615470802406502 
Hall, J. C., \& Theriot, M. T. (2007). An exploratory study evaluating the effectiveness of an innovative model for teaching multicultural social work education. Journal of Teaching in Social Work, 27(3-4), 259-271. doi:http://dx.doi.org/10.1300/J067v27n03_16

Hall, J. C. \& Theriot, M. T. (2016). Developing multicultural awareness, knowledge, and skills: Diversity training makes a difference. Multicultural Perspectives, 18(1), 35-41. doi: $10.1080 / 15210960.2016 .1125742$

Helms, J. E. (1984). Toward a theoretical explanation of the effects of race on counseling: A Black and White model. Counseling Psychologist, 12, 153-165.

Jani, J. S., Osteen, P., \& Shipe, S. (2016). Cultural competence and social work education: Moving toward assessment of practice behaviors. Journal of Social Work Education, $52(3), 311-324$.

Jeyasingham, D. (2012). White noise: A critical evaluation of social work education's engagement with Whiteness studies. British Journal of Social Work, 42(4), 669-686.

Jones, L. V., Hopson, L., Warner, L., Hardiman, E. R., \& James, T. (2015). A qualitative study of Black women's experiences in drug abuse and mental health services. Affilia: Journal of Women \& Social Work, 30(1), 68-82.

Kmet L.M., Lee R.C. \& Cook L.S. (2004) Standard quality assessment criteria for evaluating primary research papers from a variety of fields. Alberta Heritage Foundation for Medical Research, Alberta. Retrieved from: http://www.ihe.ca/advanced-search/standardquality-assessment-criteria-for-evaluating-primary-research-papers-from-a-variety-offields 
Larson, K. E., \& Bradshaw, C. P. (2017). Cultural competence and social desirability among practitioners: A systematic review of the literature. Children and Youth Services Review, 76, 100-111. doi:10.1016/j.childyouth.2017.02.034

Lee, E.-K. O. (2014). Use of avatars and a virtual community to increase cultural competence. Journal of Technology in Human Services, 32(1-2), 93-107.

Lee, E. O., \& Priester, M. (2014). Who is the help today?: Use of film to explore diversity. Affilia: Journal of Social Work and Women, 29, 92-104.

Lee, E.-K. O., Brown, M., \& Bertera, E. M. (2010). The use of an online diversity forum to facilitate social work students' dialogue on sensitive issues: A quasi-experimental design. Journal of Teaching in Social Work, 30(3), 272-287.

Leon-Guerrero, A. (2009). Social problems: Community, policy and social action (2nd ed.). Thousand Oaks, CA: Pine Forge Press.

Littell, J. H., Corcoran, J., \& Pillai, V. (2008). Systematic reviews and meta-analysis. New York, NY: Oxford University Press.

Lopez-Humphreys, M. (2011). Intergroup dialogue: An evaluation of a pedagogical model for teaching cultural competence within a framework of social justice in social work programs. (Doctoral dissertation). Retrieved from Dissertation Abstracts International Section A, 72, 1780 .

Loya, M. A., \& Cuevas, M. (2010). Teaching racism: Using experiential learning to challenge the status quo. Journal of Teaching in Social Work, 30(3), 288-299.

Mapp, S. C. (2012). Effect of short term study abroad programs on students' cultural adaptability. Journal of Social Work Education, 48(4), 727-737. 
Melendez, M. P. (2007). Describing the impact of required diversity courses on beginning social work students developing multicultural competence. (Doctoral dissertation). Retrieved from ProQuest Information \& Learning, U.S. (3270643).

Mehrotra, G. R., Hudson, K. D., \& Self, J. M. (2017). What are we teaching in diversity and social justice courses? A qualitative content analysis of MSW syllabi. Journal of Teaching in Social Work, 37(3), 218-233. doi:10.1080/08841233.2017.1316342

Mezirow J. (2000). Learning to think like an adult: Core concepts of transformative theory. In J. Mezirow (Ed.), Learning as transformation: Critical perspectives on a theory in progress (pp. 3-33). San Francisco, CA: Jossey-Bass Publishers.

Moher, D., Liberati, A, Tetzlaff, J., Altman D.G., The PRISMA Group (2009). Preferred Reporting Items for Systematic Reviews and Meta-Analyses: The PRISMA Statement. PLoS Med 6 (7): e1000097. doi:10.1371/journal.pmed1000097

National Association of Social Workers [NASW]. (2007). Indicators for the achievement of the NASW standards for cultural competence in social work practice. Washington, DC: NASW.

National Association of Social Workers [NASW]. (2011). Social work salaries by race \& ethnicity: Occupational profile. Retrieved from https://www.socialworkers.org/LinkClick.aspx?fileticket=m_S90OGQss\%3D\&portalid=0

National Association of Social Workers [NASW]. (2015). Standards and indicators for cultural competence in social work practice. Retrieved from https://www.socialworkers.org/LinkClick.aspx ?fileticket=PonPTDEBrn4\%3D\&portalid= 0 
Nylund, D. (2006). Critical multiculturalism, Whiteness, and social work: Towards a more radical view of cultural competence. Journal of Progressive Human Services, 17(2), 2742.

Ortiz, L., \& Jani, J. (2010). Critical race theory: A transformational model for teaching diversity. Journal of Social Work Education, 46(2), 175-193. doi:10.5175/JSWE.2010.200900070

Osteen, P. J., Vanidestine, T. J., \& Sharpe, T. L. (2013). Multicultural curriculum and MSW students' attitudes about race and diversity. Journal of Teaching in Social Work, 33(2), 111-128.

Padilla, Y. C. (1990). Social science theory on the Mexican-American experience. The Social Service Review, 64(2), 261.

Pewewardy, N. (2007). Challenging White privilege: critical discourse for social work education. Alexandria, VA: Council on Social Work Education.

Phillips, A., Peterson, S., Bakko, M., \& Clark, T. (2011). Promoting cultural competencies through use of growth groups in predominantly White classrooms. Journal of Baccalaureate Social Work, 16(2), 35-54.

Pulliam, R. M. (2017). Practical application of critical race theory: A social justice course design. Journal of Social Work Education, 53(3), 414. doi:10.1080/10437797.2016.1275896

Quinn-Lee, L., \& Olson-McBride, L. (2012). The effect of domestic immersion experiences on levels of cultural competence. The Journal of Baccalaureate Social Work, 17, 119-132.

Rahill, G. J., Joshi, M., Lucio, R., Bristol, B., Dionne, A., \& Hamilton, A. (2016). Assessing the development of cultural proficiency among upper-level social work students. Journal of Social Work Education, 52(2), 198-213. 
Rodenborg, N. A. \& Boisen, L.A. (2013). Aversive racism and intergroup contact theories: cultural competence in a segregated world. Journal of Social Work Education 49(4), 564579.

Saleh, M. F., Anngela-Cole, L., \& Boateng, A. (2011). Effectiveness of diversity infusion modules on students' attitudes, behavior, and knowledge. Journal of Ethnic \& Cultural Diversity in Social Work, 20(3), 240-257.

Salsberg, E., Quigley, L., Mehfoud, N., Acquaviva, K. D., Wyche, K., \& Silwa, S. (2017). Profile of the Social Work Workforce. Health Workforce Institute and School of Nursing. The George Washington University. Retrieved from https://hsrc.himmelfarb.gwu.edu/sphhs_policy_workforce_facpubs/16

Schuldberg, J., Fox, N. S., Jones, C. A., Hunter, P., Mechard, M. Stratton, M. (2012). Same, same but different: The development of cultural humility through an international volunteer experience. International Journal of Humanities and Social Science, 2(17), 13.

Spencer, S. (2006). Race and ethnicity: Culture, identity and representation. Milton Park, England: Routledge.

Sue, D. W. (2006). Multicultural social work practice. Hoboken, N.J: Wiley.

Sue, D. W. \& Sue, D. (2016). Counseling the culturally diverse: Theory and practice (7th Edition). New York, NY: John Wiley \& Sons Inc.

Tervalon, M., \& Murray-García, J. (1998). Cultural humility versus cultural competence: A critical distinction in defining physician training outcomes in multicultural education. Journal of Health Care for the Poor and Underserved, 9(2), 117-125. doi: 10.1353/hpu.2010.0233 
The People's Institute for Survival and Beyond. (2018). Undoing racism. Retrieved from http://www.pisab.org/

University of Michigan. (2018). The National Intergroup Dialogue Institute. Retrieved from https://igr.umich.edu/article/national-intergroup-dialogue-institute

Varghese, R. (2016). Teaching to transform? Addressing race and racism in the teaching of clinical social work practice. Journal of Social Work Education, 52, S134-S147.

Viruell-Fuentes, E. A., Miranda, P. Y., \& Abdulrahim, S. (2012). More than culture: Structural racism, intersectionality theory, and immigrant health. Social Science \& Medicine, 75(12), 2099-2106.

Warde, B. (2012). The cultural genogram: Enhancing the cultural competency of social work students. Social Work Education, 31(5), 570-586. doi:10.1080/02615479.2011.593623

Williams, C. C. (2006). The epistemology of cultural competence. Families in Society, 87(2), 209-220.

Williams, J., Simon, C., \& Bell, A. (2015). Missing the mark: The image of the social work profession in an African-American community. Journal of Ethnic \& Cultural Diversity in Social Work, 24(1), 56-70.

Williams-Gray, B. (2014). Teaching note: Ethnic sharing: Laying the foundation for culturally informed practice with BSW students. The Journal of Baccalaureate Social Work, 19, 151-159.

Wear, D. (2003). Insurgent multiculturalism: rethinking how and why we teach culture in medical education. Academic Medicine, 78, 549-554.

Weaver, H. N. (1998). Teaching cultural competence: Application of experiential learning techniques in social work. Journal of Teaching in Social Work, 17, 65-79. 